\title{
New onset diabetes after transplantation (NODAT): an overview
}

This article was published in the following Dove Press journal:

Diabetes, Metabolic Syndrome and Obesity: Targets and Therapy 12 May 2011

Number of times this article has been viewed

\author{
Phuong-Thu T Pham' \\ Phuong-Mai T Pham ${ }^{2,3}$ \\ Son $\mathrm{V}$ Pham ${ }^{4}$ \\ Phuong-Anh T Pham ${ }^{5}$ \\ Phuong-Chi T Pham ${ }^{2,6}$ \\ 'Nephrology Division, Kidney \\ Transplant Program, Department of \\ Medicine, David Geffen School of \\ Medicine at UCLA, Los Angeles, CA; \\ ${ }^{2}$ David Geffen School of Medicine at \\ UCLA, Los Angeles, CA; ${ }^{3}$ Department \\ of Medicine, Greater Los Angeles \\ VA Medical Center, Los Angeles, CA; \\ ${ }^{4}$ Division of Cardiology, Bay Pines \\ VA Medical Center, Bay Pines, FL; \\ ${ }^{5}$ Division of Cardiology, Memphis \\ VA Medical Center, Memphis, TN; \\ ${ }^{6}$ Department of Medicine, Nephrology \\ Division, UCLA Olive View Medical \\ Center, Los Angeles, CA, USA
}

Correspondence: Phuong-Thu T Pham Associate Clinical Professor of Medicine, Director of Outpatient Services, David Geffen School of Medicine at UCLA, Kidney Transplant Program, Los Angeles, CA 90095, USA

Tel + I 3107941757

Email ppham@mednet.ucla.edu

\begin{abstract}
Although renal transplantation ameliorates cardiovascular risk factors by restoring renal function, it introduces new cardiovascular risks including impaired glucose tolerance or diabetes mellitus, hypertension, and dyslipidemia that are derived, in part, from immunosuppressive medications such as calcineurin inhibitors, corticosteroids, or mammalian target of rapamycin inhibitors. New onset diabetes mellitus after transplantation (NODAT) is a serious and common complication following solid organ transplantation. NODAT has been reported to occur in $2 \%$ to $53 \%$ of all solid organ transplants. Kidney transplant recipients who develop NODAT have variably been reported to be at increased risk of fatal and nonfatal cardiovascular events and other adverse outcomes including infection, reduced patient survival, graft rejection, and accelerated graft loss compared with those who do not develop diabetes. Identification of high-risk patients and implementation of measures to reduce the development of NODAT may improve long-term patient and graft outcome. The following article presents an overview of the literature on the current diagnostic criteria for NODAT, its incidence after solid organ transplantation, suggested risk factors and potential pathogenic mechanisms. The impact of NODAT on patient and allograft outcomes and suggested guidelines for early identification and management of NODAT will also be discussed.
\end{abstract}

Keywords: new onset diabetes after transplantation (NODAT), cyclosporine, tacrolimus, sirolimus, hepatitis $\mathrm{C}$ and diabetes, cytomegalovirus and diabetes

\section{Definition and diagnosis of new onset diabetes after transplantation}

Over the years, the precise incidence of new onset diabetes after transplantation (NODAT) has been difficult to determine due to the lack of a standard definition for the condition. Historically, post-transplant diabetes has been variably defined as having random glucose levels greater than $200 \mathrm{mg} / \mathrm{dL}$ or fasting glucose levels greater than $140 \mathrm{mg} / \mathrm{dL}$, or the need for insulin or oral hypoglycemic agents in the post-transplant period. In 2003, the International Expert Panel consisting of experts from both the transplant and diabetes fields set forth the International Consensus Guidelines for the diagnosis and management of NODAT. ${ }^{1,2}$ It was recommended that the definition and diagnosis of NODAT should be based on the definition of diabetes mellitus and impaired glucose tolerance (IGT) described by the World Health Organization (WHO). ${ }^{2,3}$ The current WHO and American Diabetes Association (ADA) guidelines for the diagnosis of prediabetic states (impaired fasting glucose (IFG) and IGT) and diabetes mellitus are provided in Table 1. 
Table I WHO and 2003 updated ADA criteria for the diagnosis of diabetes mellitus

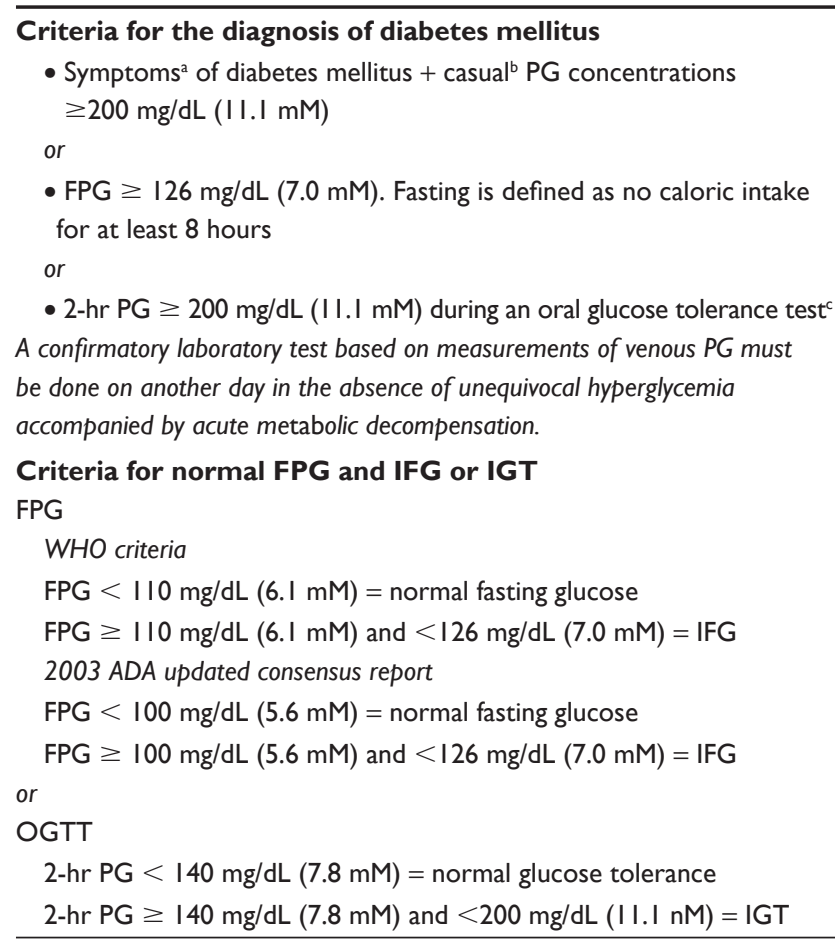

Notes: ${ }^{a}$ Classic symptoms of diabetes include polyuria, polydipsia, and unexplained weight loss; ${ }^{\circ}$ Casual is defined as any time of day without regard to time since last meal; ' OGTT: the test should be performed as described by WHO, using a glucose load containing equivalent of $75 \mathrm{~g}$ anhydrous glucose dissolved in water.

Copyright (c) 2003, Wolters Kluwer Health. Reproduced with permission from Davidson et al.'

Abbreviations: WHO, World Health Organization; PG, plasma glucose; FPG, fasting plasma glucose; IFG, impaired fasting glucose; IGT, impaired glucose tolerance; OGTT, oral glucose tolerance test.

\section{Incidence}

New onset diabetes mellitus after transplantation has been reported to occur in $4 \%$ to $25 \%$ of renal transplant recipients, $2.5 \%$ to $25 \%$ of liver transplant recipients, $4 \%$ to $40 \%$ of heart transplant recipients, and $30 \%$ to $35 \%$ of lung transplant recipients. ${ }^{1,4-6}$ The variation in the reported incidence may be due in part to the lack of a standard definition of the condition, the duration of follow-up, the presence of both modifiable and non-modifiable risks factors, and the type of organ transplants. In hepatitis C virus (HCV)-infected liver recipients, the prevalence of NODAT has been reported to range between $40 \%$ to $60 \%{ }^{4,5,7}$ Similar to the nontransplant settings, the use of fasting plasma glucose (FPG) versus oral glucose tolerance test (OGTT) to define diabetes mellitus also changes the prevalence of NODAT. In a prospective study designed to evaluate the use of OGTT for risk-stratifying patients for NODAT, Sharif et $\mathrm{al}^{8}$ demonstrated that among 122 renal transplant recipients without diabetes who had two fasting plasma glucose (FPG) level measurements within the range of $100-125 \mathrm{mg} / \mathrm{dL}(5.6-6.9 \mathrm{mmol} / \mathrm{L})$ for more than 6 months after transplantation, OGTTs revealed that $10 \%$ had overt diabetes mellitus, $9 \%$ had IGT alone, $18 \%$ had IFG alone (all defined by WHO criteria), and 14\% had combined IFG and IGT.

\section{Risk factors for NODAT}

Risk factors for the development of NODAT are categorized as non-modifiable, modifiable or potentially modifiable, the former category to facilitate the identification of high risk individuals, and the latter two categories to optimize the management of NODAT. Suggested risk factors for NODAT are summarized in Figure 1.

\section{Nonmodifiable risk factors}

Age

Older age has long been observed to be an important risk factor for the development of NODAT. Cosio et $\mathrm{al}^{9} \mathrm{dem}$ onstrated that transplant recipients older than 45 years of age were 2.2 times more likely to develop NODAT than those younger at the time of transplantation $(P<0.0001)$. Similarly, in an analysis of the US Renal Data System (USRDS) consisting of over 11,000 Medicare beneficiaries who received primary kidney transplants between 1996 and 2000, Kasiske et $\mathrm{al}^{10}$ showed a strong association between older age and NODAT. Compared to a reference range of 18-44 years of age, transplant recipients between the age of 45-59 years had a relative risk for NODAT of 1.9 $(P<0.0001)$, whereas those who were $\geq 60$ years of age had a relative risk of $2.09(P<0.0001){ }^{9}$

\section{Race/ethnicity}

There has been ample literature suggesting that African Americans and Hispanics are at increased risk for developing

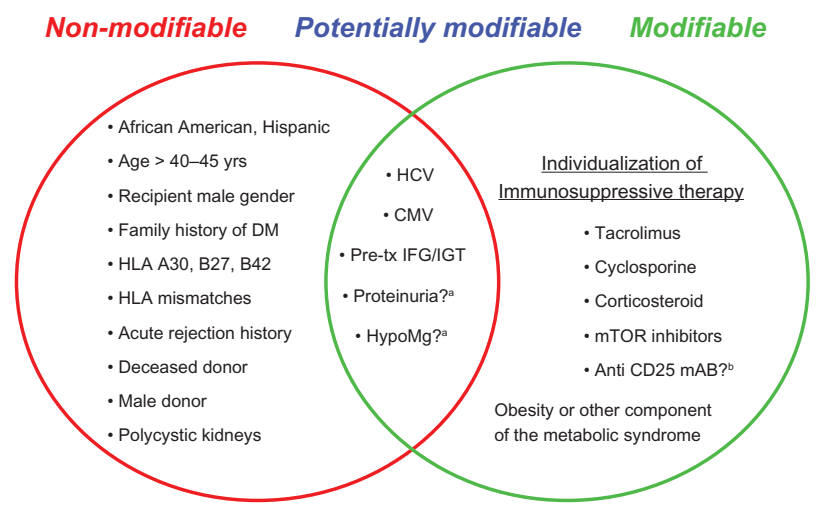

Figure I Risk factors for NODAT.

Abbreviations: Anti CD25 mAb? , Anti CD25 monoclonal antibody; CMV, cytomegalovirus; HCV, hepatitis C; HypoMg, hypomagnesemia; Pre-Tx, pre-transplant. Notes: Restoration of insulin metabolism by a functioning graft may unmask pre-transplant impaired glucose tolerance or diabetes and is not a risk factor per se. aSee text. 'burther studies are needed 
NODAT compared to whites. In a single-center retrospective study consisting of 122 renal transplant recipients, the risk of developing NODAT as defined by the 2003 International guidelines was double in African Americans compared to whites. ${ }^{11}$ Similarly, data from the USRDS demonstrated that NODAT was more common among African Americans $(\mathrm{RR}=1.68, P<0.0001)$ and Hispanics $(\mathrm{RR}=1.35$, $P<0.0001)$ compared with Caucasians. The difference in the incidence of NODAT in patients of different ethnicity has been suggested to be due in part to the differential pharmacokinetics and diabetogenic effects of immunosuppressive agents. ${ }^{3}$ Tacrolimus has also been reported to have particularly potent diabetogenic effects in African Americans compared with whites. ${ }^{1}$ It is also possible that cultural differences in lifestyle may be contributory.

\section{Family history of diabetes mellitus}

Similar to type 2 diabetes in the general population, both genetic and environmental factors have been suggested to play a role in the development of NODAT. There is strong evidence suggesting that individuals with a family history of diabetes among first-degree relatives have an increased risk of developing NODAT, with one study reporting a sevenfold increase in the condition. ${ }^{1}$ The increased prevalence of NODAT associated with a family history of diabetes has been documented across all types of solid organ transplantation. In a Spanish multicenter cross-sectional study consisting of 1410 recipients of kidney transplants, 489 liver transplants, 207 heart transplants, and 72 lung transplants, a positive family history of diabetes was associated with a $50 \%$ increase in the risk of developing NODAT (odds ratio of 1.51). ${ }^{12}$

Other non-modifiable risk factors include recipient male gender; the presence of certain human leukocyte antigens (HLA) such as HLA A30, B27, and B42; increasing HLA mismatches; donor-recipient (DR) mismatch; deceased donor kidneys; male donor; and acute rejection history. ${ }^{13}$ Polycystic kidney disease has been suggested to confer an increased risk of developing diabetes after renal transplantation in some studies but not in others. ${ }^{14-17}$

\section{Modifiable risk factors}

\section{Corticosteroid-associated NODAT}

The now well-established contributory role of corticosteroids on NODAT was first described by Starlz in 1964 in renal transplant recipients. ${ }^{9,18}$ The diabetogenic effect of corticosteroids has been suggested to be dose-dependent. Single-center studies have demonstrated that oral prednisolone dose reduction to $5 \mathrm{mg}$ daily significantly improves glucose tolerance during the first year after transplantation ${ }^{19}$ while a $0.01 \mathrm{mg} / \mathrm{kg} /$ day increase in prednisolone dose is associated with a $5 \%$ risk of developing NODAT. ${ }^{20}$

In a small study involving 57 stable renal transplant recipients, Midtvedt and colleagues ${ }^{21}$ found that prednisolone dose reduction from a mean of $16 \mathrm{mg}$ daily (range 10 to 30 ) to $9 \mathrm{mg}$ daily (range 5 to 12.5 ) resulted in an average increase in insulin sensitivity index of $24 \%$. However, complete withdrawal of $5 \mathrm{mg}$ /day of prednisolone did not influence insulin sensitivity significantly. Whether complete withdrawal of chronic low dose corticosteroid therapy (prednisolone $5 \mathrm{mg}$ daily) improves glucose metabolism remains to be studied. Nonetheless, in recent years several studies have suggested a potential beneficial effect of steroid-free immunosuppression on NODAT risk reduction. ${ }^{22}$

In a retrospective analysis of the Organ Procurement Transplant Network/Scientific Registry of Transplant Recipient (OPTN/SRTR) database consisting of $>25,000$ kidney transplant recipients engrafted between January 2004 and December 2006, Luan et $\mathrm{al}^{22}$ demonstrated that steroidfree immunosuppression was associated with a significant reduction in the likelihood of developing NODAT compared with steroid-containing regimens. The cumulative incidence of NODAT within three years post-transplant were $12.3 \%$ in steroid-free versus $17.7 \%$ in steroid-containing regimens, $P<0.001$. Overall, steroid-containing regimens at the time of hospital discharge were associated with a $42 \%$ increased risk for NODAT. Notably, patients from programs that frequently adopted steroid-free regimens had reduced odds of NODAT compared with those from programs that commonly used steroid-containing regimens.

The dose dependent diabetogenic effect of corticosteroids was also observed in recipients of nonrenal organ transplants. In a retrospective review involving 88 heart transplant recipients, Depcynski and colleagues ${ }^{23}$ found that patients who developed NODAT had received higher mean doses of prednisolone at 3 months compared with those who remained free of diabetes at a mean follow-up of 27 months $(0.21 \pm 0.03$ versus $0.19 \pm 0.03 \mathrm{mg} / \mathrm{kg} / \mathrm{day}, P<0.01)$.

\section{Calcineurin inhibitor(CNI)-associated NODAT: cyclosporine versus tacrolimus}

Although clinical trials comparing the incidence of NODAT in cyclosporine A (CSA)- versus tacrolimus (Tac)-treated patients have yielded mixed results, Tac has more consistently been shown to have a greater diabetogenic effect. ${ }^{24,25}$

The DIRECT Study (Diabetes Incidence after Renal Transplantation: Neoral C2 monitoring versus Tacrolimus) 
was the first multi-center open label, randomized trial to assess glucose abnormalities in de novo kidney transplant patients who were randomized to cyclosporine microemulsion(CSA-ME) or tacrolimus-based immunosuppression. ${ }^{26}$ The incidence of NODAT or IFG (defined by WHO/ADA criteria) at 6-month post-transplant was significantly lower in CSA-ME- versus tacrolimus- treated patients, $(26 \%$ versus $33.6 \%, P=0.046)$. Furthermore, a lower proportion of CSA-ME patients with NODAT required hypoglycemic medication or dual therapy with insulin and oral hypoglycemic agents compared with their tacrolimus-treated counterparts.

The greater diabetogenic effect of tacrolimus compared to CSA has been reported to occur across renal and nonrenal transplant groups. In a meta-analysis to evaluate the reported incidence of NODAT after solid organ transplantation, Heisel and colleagues ${ }^{27}$ found a higher incidence of insulindependent diabetes mellitus (IDDM) in Tac- versus CSAtreated liver, heart, and lung transplant recipients. In renal transplant recipients, IDDM occurred in $9.8 \%$ of Tac-treated versus. $2.7 \%$ of CSA-treated patients $(P<0.00001)$. Similar trends were observed among recipients of non renal organ transplants $(11.1 \%$ versus $6.2 \%$, respectively $(P<0.003)$. Nonetheless, not all studies showed that Tac is more diabetogenic than cyclosporine. ${ }^{28}$ It has been suggested that these study inconsistencies partially stemmed from the difference in the definitions of NODAT and the difference in calcineurin inhibitor dose and drug levels. ${ }^{28,29}$ In a single-center study consisting of 139 renal transplant recipients without known pretransplant glucose abnormalities, Maes and colleagues ${ }^{29}$ have shown that high Tac trough levels, particularly levels greater than $15 \mathrm{ng} / \mathrm{mL}$ in the first month after transplant, were a significant risk factor for persistent impaired fasting glucose or diabetes mellitus beyond the first year after transplantation. In a single-center study consisting of 45 orthotopic liver transplant (OLT) recipients treated with either CSA $(n=9)$ or high- $(n=15)$ versus. low- $(n=13)$ dose Tac, the incidence of NODAT was $11 \%, 40 \%$ and $23 \%$, respectively. ${ }^{30}$

\section{Interaction between tacrolimus and concomitant hepatitis $\mathrm{C}$ infection ( $\mathrm{HCV}$ )}

In a retrospective study of more than 400 kidney transplant recipients with no known pre-transplant diabetes, Bloom and colleagues $^{31}$ have shown that among the HCV-positive cohort, NODAT occurred more often in the Tac- compared with the CSA-treated groups $(57.8 \%$ versus $7.7 \%, P<0.0001)$. In contrast, among the $\mathrm{HCV}$-negative cohort, the rates of NODAT were similar between the two calcineurin inhibitor
(CNI) groups (Tac versus CSA: 10\% vs 9.4\%, respectively, $P=0.521)$. Whether concomitant exposure to tacrolimus and HCV plays a synergistic role in the development of NODAT remains speculative.

\section{Effects of sirolimus (Sir) on glucose metabolism}

Early large randomized clinical trials suggested that sirolimus is devoid of diabetogenic effects either used alone or in combination therapy with CNI. However, the diabetogenicity of sirolimus has now been well-described. Teutenico et al ${ }^{32}$ demonstrated that calcineurin inhibitors to sirolimus conversion therapy and tacrolimus withdrawal in a regimen consisting of tacrolimus and sirolimus were associated with a $30 \%$ increased incidence of impaired glucose tolerance. In one single-center study, tacrolimus and sirolimus combination therapy was found to be associated with a higher incidence of NODAT than tacrolimus immunosuppression alone. ${ }^{11}$ Subsequent large registry studies also demonstrated an association between sirolimus and the development of NODAT. In an analysis of the USRDS database consisting of more than 20,000 primary kidney transplant recipients receiving sirolimus or CNI (CsA or Tac) or both in various combination therapies with an antimetabolite [mycophenolate mofetil (MMF) or azathioprine (AZA)], Johnston et $\mathrm{l}^{33}$ demonstrated that patients treated with sirolimus in combination with a CNI (CsA or Tac) had the highest incidence of NODAT. The authors further demonstrated that patients treated with (Sir + Tac) combination therapy had a hazard ratio of developing NODAT of 1.9 compared with those receiving (Tac + MMF/AZA), suggesting that sirolimus was associated with an increased risk for NODAT independent of any effect of tacrolimus.

\section{Effects of antimetabolites on NODAT}

The antimetabolites AZA and MMF have not been shown to be diabetogenic. On the contrary, the concomitant use of MMF has been suggested to mitigate the diabetogenic effect of tacrolimus. ${ }^{10}$ It is conceivable that the use of azathioprine or MMF allows clinicians to use lower doses of other diabetogenic immunosuppressive medications.

\section{Potential pathogenic mechanisms of $\mathrm{CNI}$ and mammalian target of rapamycin (mTOR) inhibitor-induced NODAT}

An extensive discussion of the pathogenic mechanisms of immunosuppressive drug-induced NODAT is beyond the scope of the current manuscript. A summary of suggested mechanisms is shown in Table 2. 
Table 2 Drug-induced NODAT: potential pathogenic mechanism(s)

\begin{tabular}{|c|c|c|}
\hline $\begin{array}{l}\text { Immunosuppressive } \\
\text { agent }\end{array}$ & $\begin{array}{l}\text { Pathogenic } \\
\text { mechanism(s) }\end{array}$ & Comments \\
\hline Corticosteroids & $\begin{array}{l}\text { - } \downarrow \text { Peripheral insulin } \\
\text { sensitivity } \\
\text { - Inhibit pancreatic } \\
\text { insulin production } \\
\text { and secretion } \\
\text { - } \uparrow \text { Hepatic } \\
\text { gluconeogenesis } \\
\text { - Promote protein } \\
\text { degradation to free } \\
\text { amino acids in } \\
\text { muscle, lipolysis }\end{array}$ & $\begin{array}{l}\text { - Dose-dependent } \\
\text { - Impact of complete } \\
\text { withdrawal of } \\
\text { chronic low-dose } \\
\text { steroids unclear } \\
\text { - Potential } \downarrow \text { NODAT } \\
\text { risk in steroid-free } \\
\text { regimens }\end{array}$ \\
\hline Cyclosporine & $\begin{aligned} \text { - } & \downarrow \text { insulin secretion } \\
& (\mathrm{Cs} \mathrm{A}<\mathrm{Tac}) \\
\text { - } & \downarrow \text { insulin synthesis } \\
\text { - } & \downarrow \beta \text {-cell density }\end{aligned}$ & $\begin{array}{l}\text { - Dose-dependent, } \\
\text { - Diabetogenic effect } \uparrow \\
\text { with } \uparrow \text { steroid dose* }\end{array}$ \\
\hline Tacrolimus & $\begin{array}{l}\text { - } \downarrow \text { insulin secretion } \\
(\text { Tac }>\text { CsA) } \\
\text { - } \downarrow \text { insulin synthesis }\end{array}$ & $\begin{array}{l}\text { - Dose-dependent, } \\
\text { - Diabetogenic effect } \uparrow \\
\text { with } \uparrow \text { steroid dose* }\end{array}$ \\
\hline Sirolimus & $\begin{array}{l}\text { - } \text { Peripheral insulin } \\
\text { resistance } \\
\text { - Impair pancreatic } \\
\beta \text {-cell response }\end{array}$ & $\begin{array}{l}\text { - } \text { Diabetogenicity } \\
\text { when use with CNIs }\end{array}$ \\
\hline
\end{tabular}

Note: *Demonstrated in some but not all studies.

Abbreviation: $\mathrm{CNI}$, calcineurin inhibitors.

\section{Obesity}

Similar to the general population, obesity has been shown to be associated with the development of NODAT in most studies. ${ }^{34}$ Analysis of the USRDS database revealed that obesity, defined as a BMI of $\geq 30 \mathrm{~kg} / \mathrm{m}^{2}$ is one of the strongest risk factors for NODAT (Relative risk (RR) of $1.73, P<0.0001)$. Although some studies failed to demonstrate an association between obesity and the development of NODAT, obesity and its associated peripheral insulin resistance state is a known risk factor for type 2 diabetes. The mechanism whereby obesity induces insulin resistance is poorly understood. Nonetheless, the pattern of body fat distribution has been suggested to play a contributory role. Studies in healthy women showed that upper body or maletype obesity has a much greater association with insulin resistance and impaired glucose tolerance than lower body or female-type obesity. ${ }^{35}$ Similar studies in the transplant settings are lacking. It is speculated that intra-abdominal fat or waist-to-hip ratio may be more important risk factors for NODAT than total body weight or BMI.

\section{Hypertriglyceridemia/hypertension}

Early retrospective studies suggested that the greater the number of the metabolic syndrome components, the greater the risk for the development of NODAT. ${ }^{36}$ In a recent retrospective analysis consisting of 640 nondiabetic renal transplant recipients, Bayer et $\mathrm{al}^{37}$ demonstrated that the prevalence of NODAT at 1 year increased with increasing number of metabolic syndrome score 0: $0 \%, 1: 24 \%$, 2: $29 \%, 3: 31 \%, 4: 35 \%, 5: 74 \%, P=0.001$. Multivariate analysis incorporating the individual metabolic syndrome components as covariates demonstrated that of all the pre-transplant metabolic syndrome components, only lowdensity lipoprotein was independently associated with the development of NODAT.

The precise role of the metabolic syndrome or metabolic syndrome component(s) in the development of NODAT remains to be defined. Nonetheless, the overlapping metabolic risk factors for type 2 diabetes and cardiovascular disease (eg, obesity, hyperglycemia, dyslipidemia, hypertension) warrant early identification and aggressive management of individual risk factors.

\section{Proteinuria}

Early reports from a single-center study suggested an association between proteinuria on day 5 after transplantation and the development of NODAT. ${ }^{38}$ However, these findings have been challenged because proteinuria on day 5 may just reflect the highly concentrated urine associated with hyperglycemiainduced osmotic diuresis from the early posttransplant use of high dose corticosteroids or residual native kidney proteinuria. Furthermore, it has been shown that immediate posttransplant proteinuria generally resolves several weeks after transplantation. ${ }^{39}$ Nonetheless, in a subsequent singlecenter retrospective study designed to evaluate the impact of early proteinuria ( 3 and 6 months after transplantation) and urinary albumin excretion (UAE) on NODAT, Roland et al ${ }^{40}$ demonstrated that low-grade $(<1 \mathrm{~g} /$ day $)$ and very low-grade $(<0.3 \mathrm{~g} /$ day $)$ proteinuria were independent risk factors for NODAT ( $P=0.0042$ and $P=0.00025$, respectively). Furthermore, there was a dose-dependent relationship across UAE categories with NODAT. NODAT-free survival was greater in patients with normoalbuminuria than in those with microalbuminuria, and greater in those with microalbuminuria than in those with macroalbuminuria $(P=0.0326)$. The authors also demonstrated that pulse pressure was an independent risk factor for NODAT, suggesting that early low-grade proteinuria and pulse pressure may be markers of the metabolic syndrome or vascular damage or both.

\section{Hypomagnesemia}

In the general population, not only has hypomagnesemia been shown to be associated with type 2 diabetes, but 
numerous studies have also reported an inverse relationship between glycemic control and serum Mg levels. ${ }^{41}$ Similar to the nontransplant settings, hypomagnesemia has also been shown to be an independent predictor of NODAT in recipients of renal and liver transplants. In a single-center retrospective analysis consisting of 254 renal transplant recipients, Van Laecke et $\mathrm{al}^{42}$ demonstrated that hypomagnesemia during the first-month posttransplantation was associated with the development of NODAT, independent of the immunosuppressive regimen used. While the association between the use of CNIs was strongly related to hypomagnesemia, NODAT disappeared after adjustment for $\mathrm{Mg}$ levels suggesting that the diabetogenic effect of CNIs is at least in part related to hypomagnesemia. Conversely, the use of mTOR inhibitors appeared to be a risk factor for NODAT after adjustment for Mg levels. The same group of authors subsequently demonstrated that both pretransplant hypomagenesemia and hypomagnesemia in the firstmonth posttransplantation were independent predictors of NODAT in recipients of liver transplants. ${ }^{43}$ Whether $\mathrm{Mg}$ supplementation and correction of $\mathrm{Mg}$ deficiency reduce the incidence of insulin resistance or NODAT remains to be studied.

\section{Potentially modifiable risk factors} Impaired glucose tolerance before transplantation

Abnormal glucose metabolism has been reported to be a risk factor for the development of NODAT in some but not all studies. In a study consisting of 490 recipients of kidney transplants, Cosio et $\mathrm{al}^{44}$ demonstrated that higher pretransplant glucose is a risk factor for NODAT at one year. Using patients with pretransplant FPG levels between 90 and 100 as the reference group, patients with plasma glucose $<90 \mathrm{mg} / \mathrm{dL}$ have lower risk of NODAT (OR $=0.46, P=0.01)$. In contrast, the risk of NODAT increases as the pretransplant FPG levels increases $(F P G=101-109$, OR $=1.5$; and $\mathrm{FPG}=110-125, \mathrm{OR}=7.6, P<0.0001)$. Among patients with IFG pretransplant, $70 \%$ had hyperglycemia at one year (IFG $43 \%$ and NODAT 27\%).

\section{HCV-associated NODAT}

The association between HCV infection and IFG, or the development of overt type 2 diabetes mellitus in the general population, has long been suggested. Potential mechanisms for the diabetogenic effect of HCV infection include insulin resistance; decreased hepatic glucose uptake and glycogenesis; and direct cytopathic effect of the virus on pancreatic $\beta$ cells. ${ }^{45}$ Similar to the non-transplant settings, the link between hepatitis $\mathrm{C}$ and the development of NODAT has also been recognized in solid organ transplant recipients. The pathogenesis of HCV-associated NODAT, however, remains poorly understood. Clinical studies in OLT recipients have implicated insulin resistance associated with active $\mathrm{HCV}$ infection as a predominant pathogenic mechanism. Independent investigators have shown a temporal relationship between recurrent allograft hepatitis and increasing viral loads and the development of NODAT. ${ }^{4,45}$ Furthermore, patients who responded to antiviral therapy were observed to have improvement in glycemic control. ${ }^{4,46,47}$ In a small cohort of 17 nondiabetic HCV-positive and 33 non-diabetic HCV-negative OLT recipients, Baid and colleagues ${ }^{4}$ have shown that the presence of $\mathrm{HCV}$ infection was independently associated with a $62 \%$ increase in insulin resistance $(P=0.0005)$. It was suggested that the virus had a direct effect on insulin resistance as no difference in $\beta$ cell function or hepatic insulin extraction between the $\mathrm{HCV}$-positive and negative groups was observed.

In a small study consisting of 16 renal transplant candidates with sustained virologic response to interferon treatment given in the pre-transplant period, none developed NODAT at a mean follow-up of 22.5 months (range, 2 to 88 months).$^{48}$ It is conceivable that successful pre-transplant treatment of hepatitis $C$ could potentially reduce the incidence of NODAT after kidney transplantation.

\section{Cytomegalovirus-associated NODAT}

The link between cytomegalovirus (CMV) infection and the development of NODAT was first reported in 1985 in a renal transplant recipient. ${ }^{49}$ Limited studies suggested that both asymptomatic CMV infection and CMV disease are independent risk factors for the development of NODAT. In a study consisting of 160 consecutive nondiabetic renal transplant recipients who were prospectively monitored for CMV infection during the first three months after transplantation, Hjelmesaeth and colleagues ${ }^{50}$ found that asymptomatic CMV infection was associated with a four-fold increased risk of new-onset diabetes (adjusted $\mathrm{RR}=4.00 ; P=0.025)$. Patients with active CMV infection had a significantly lower median insulin release compared to their CMV negative counterparts, suggesting that impaired pancreatic $\beta$ cell insulin release may be involved in the pathogenic mechanism of CMV-associated NODAT. It is speculated that CMV-induced release of proinflammatory cytokines may lead to apoptosis and functional disturbances of pancreatic $\beta$-cells. ${ }^{51}$ 


\section{Impact of NODAT on patient and allograft outcomes}

Clinical studies evaluating the impact of NODAT on patient and allograft outcomes after solid organ transplantation have yielded variable results. Nonetheless, there has been ample literature suggesting that kidney transplant recipients who developed NODAT are at a two- to three-fold increased risk of fatal and nonfatal cardiovascular disease events as compared with nondiabetic patients. ${ }^{52,53}$ The development of NODAT has also been shown to be associated with an adverse impact on patient survival and an increased risk of graft rejection and graft loss, as well as an increased incidence of infectious complications. In a study consisting of 173 renal transplant recipients, 1-year patient survival rates in those with, versus those without NODAT were $83 \%$ versus $98 \%$, respectively $(P<0.01) .{ }^{54}$ Data from the United Renal Data System consisting of over 11,000 Medicare beneficiaries who received primary kidney transplants between 1996 and 2000 demonstrated that compared to "no diabetes", NODAT was associated with a $63 \%$ increased risk of graft failure $(P<0.0001)$, a $46 \%$ increased risk of death-censored graft failure $(P<0.0001)$ and an $87 \%$ increased risk of mortality $(P<0.0001){ }^{10}$

In contrast to earlier reports, a retrospective analysis of the UNOS/OPTN database (involving patients transplanted between 2004-2007) failed to demonstrate the negative impact of NODAT on transplant survival or CV mortality during a median follow-up of 548 days. The study consisted of $>37,000$ renal transplant recipients with a functioning transplant for at least 1 year. Risk stratification according to diabetes status (pre-transplant diabetes, NODAT) and acute rejection (AR) at 1 year demonstrated that pre-transplant diabetes is the major predictor of all-cause and cardiovascular mortality, whereas acute rejection during the first year is the major predictor of death-censored transplant failure. In contrast, NODAT alone was not associated with any adverse outcomes specified in the study. ${ }^{55}$ Nonetheless, the study results were considered inconclusive given the wide confidence intervals and relatively short duration of follow-up.

\section{Detection and management of diabetes mellitus in recipients of solid organ transplants Pre-transplant baseline evaluation}

The 2004 updated International Consensus Guidelines on New-onset Diabetes after Transplantation suggest that a pre-transplant baseline evaluation should include a complete medical and family history, including documentation of glucose history. ${ }^{2}$ FPG should be tested at regular intervals and a 2-hour oral glucose tolerance test (OGTT) be performed in those with normal FPG. It has been suggested that the OGTT diagnostic criteria may be more sensitive in identifying patients with IGT than those set for FPG. ${ }^{1}$ Patients with evidence of IGT or abnormal OGTT before transplantation should be counseled on lifestyle modifications including weight control, diet, and exercise. The goals for the life-style modification involved achieving and maintaining a weight reduction of at least 7 percent of initial body weight through a healthy low-calorie, low-fat diet and at least 150 minutes of physical activity per week.

Pre-transplant treatment of $\mathrm{HCV}$-infected renal transplant candidates should be considered. Selection of an immunosuppressive regimen should be tailored to each individual patient, weighing the risk of developing diabetes after transplantation against the risk of acute rejection. Suggested pretransplant baseline evaluation of potential transplant candidates is shown in Figure 2.

\section{Early detection of NODAT after transplantation}

Studies investigating the best predictive tools for identifying patients at risk for developing NODAT early after transplantation are currently lacking. While FPG is readily available, in clinical practice it may be normal in kidney transplant recipients with abnormal glucose homeostasis. It has been suggested that transplant patients have an atypical form of insulin resistance and their plasma glucose often peaks before lunch. Hence, the use of FPG alone may preclude the accurate diagnosis of NODAT. Kuypers et $\mathrm{al}^{38}$ demonstrated that a normal (versus diabetic) OGTT on day 5 was associated

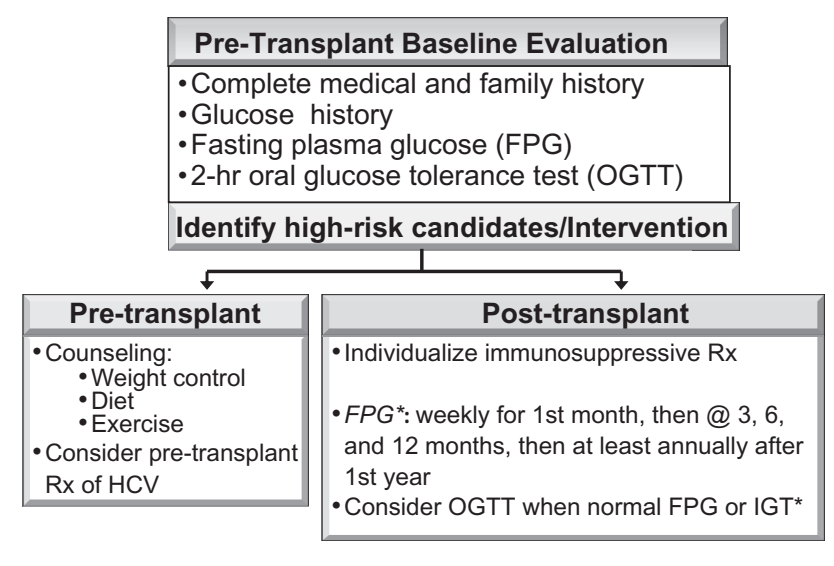

Figure 2 Suggested pretransplant baseline evaluation of potential transplant candidates. Note: *2003 International Consensus Guidelines. 
with a significantly reduced risk for NODAT (odds ratio $0.03, P=0.0002$ ). However, it is noteworthy that while acute rejection has been suggested to increase the risk for NODAT, it usually does not occur before day 5. Obtaining OGTT and FPG at day 5, therefore, may fail to detect the subset of patients with higher risk of developing NODAT. Hence, it has been suggested that performing OGTT at 10-12 weeks posttransplantation might be useful as an alternative or supplementary test to day 5 OGTT. ${ }^{56}$

The routine recommendation of performing an OGTT soon after transplantation needs further investigation. Suggested pretransplant baseline evaluation and posttransplant screening for NODAT is shown in Figure 2.

\section{Management of established NODAT}

The management of NODAT should follow the conventional approach for patients with type 2 diabetes mellitus as recommended by many clinical guidelines established by well-recognized organizations including the American Diabetes Association (ADA).

Similar to the nontransplant settings, a target hemoglobin A1C level $<6.5 \%$ is recommended. Fasting plasma glucose should be below $100 \mathrm{mg} / \mathrm{dL}$ (6.11 mmol/L), and a 2-hour postprandial plasma glucose should be below $140 \mathrm{mg} / \mathrm{dL}(7.77 \mathrm{mmol} / \mathrm{L}) .{ }^{57}$ Nonetheless, it should be noted that the Action to Control Cardiovascular Risk in Diabetes (ACCORD) trial was discontinued prematurely because of a statistically significant increase in all-cause mortality in the intensive- compared with the standard-glycemic treatment groups. ${ }^{58}$ At 1 year, stable median A1C levels of $6.4 \%$ and $7.5 \%$ were achieved in the intensive-therapy and standard groups, respectively. The intensive-therapy group had a relative increase in mortality of $22 \%$ and an absolute increase of $1.0 \%$ during a follow-up period of 3.5 years. Death from cardiovascular causes was similar between the two treatment groups. It is also notable that hypoglycemia requiring assistance and weight gain of more than $10 \mathrm{~kg}$ was more frequent in the intensive-therapy group $(P<0.001)$. Long-term follow-up of the ACCORD study demonstrated that intensive therapy failed to reduce the risk of advanced measures of microvascular outcomes but delayed the onset of micro- and macro-albuminuria and some measures of ocular complications and peripheral neuropathy, which persisted over the 5 year study period despite the transition from intensive to conventional treatment of glycemia after 3.7 years. ${ }^{59}$

Studies similar to that of the ACCORD study in recipients of solid organ transplantation are lacking. Nonetheless, the determination of hemoglobin A1C target levels for solid organ transplant recipients should be individualized based on hypoglycemia risks.

\section{Modifiable risk factor management strategy \\ Dietary modification and physical activity}

The Diabetes Prevention Program has demonstrated that a structured diet and physical activity program that achieves and maintains modest weight loss for overweight adults with IGT can significantly reduce the development of diabetes. Defining realistic goals such as a target weight loss of $5 \%-10 \%$ of total body weight, and a patient-centered approach to education, may be invaluable in achieving success. Suggested non-insulin management of NODAT is shown in Table 3.

\section{Modification of immunosuppression}

Modification of immunosuppression should be considered in high-risk patients. Corticosteroid dose reduction has been shown to significantly improve glucose tolerance during the first year after transplantation. ${ }^{10}$ However, any dose reduction should be weighed against the risk of acute rejection. Steroid-sparing regimens or steroid avoidance protocols should be tailored to each individual patient. Tac to CSA conversion therapy in patients who fail to achieve target glycemic control or in those with difficult to control diabetes has yielded variable results. The use of CNI and mTOR inhibitor combination therapy should probably be avoided.

\section{Renin-angiotensin inhibition}

A meta-analysis of 10 randomized controlled trials to assess the effects of renin angiotensin inhibition [five with angiotensin-converting enzyme inhibitors (ACEIs) and five with angiotensin receptor blockers (ARBs)] on the incidence of new cases of type 2 diabetes mellitus in patients with arterial hypertension and congestive heart failure demonstrated that renin-angiotensin inhibition with either ACEIs or ARBs consistently and significantly reduced the incidence of type 2 diabetes mellitus compared with placebo, beta-blockers/ diuretics or amlodipine. ${ }^{60}$ This finding has not yet been validated in either transplant recipients or prospective trials in the general population. ${ }^{61}$ Similarly, data regarding direct renin inhibition on NODAT are lacking. Nonetheless, ACEI and ARB are widely used due to their well-established antiproteinuric, cardioprotective, and blood pressure lowering effects. 
Table 3 Non-insulin drug therapy for NODAT

\begin{tabular}{|c|c|c|}
\hline Agents & Action & Adverse effects/comments \\
\hline \multicolumn{3}{|l|}{ INSULIN SENSITIZERS } \\
\hline (eg, Metformin, Butoformin, Phenformin) & $\begin{array}{l}\downarrow \text { hepatic glucose production, } \\
\uparrow \text { glucose uptake by skeletal muscle }\end{array}$ & $\begin{array}{l}\text { - Diarrhea, dyspepsia, lactic acidosis w/renal } \\
\text { insufficiency } \\
\text { - No weight gain, no hypoglycemia }\end{array}$ \\
\hline \multicolumn{3}{|l|}{ INSULIN SECRETAGOGS } \\
\hline $\begin{array}{l}\text { Sulfonylureas (SUs) } \\
\text { (eg, Glipizide, Glyburide, Glimepiride) }\end{array}$ & $\uparrow$ pancreatic insulin secretion & $\begin{array}{l}\text { SUs: weight gain, edema, hypoglycemia (esp. in renal } \\
\text { insufficiency and elderly) }\end{array}$ \\
\hline $\begin{array}{l}\text { Meglitinides } \\
\text { (eg, Repaglinide, Nateglinide) }\end{array}$ & & $\begin{array}{l}\text { Meglitinides: weight gain, hypoglycemia (lower risk } \\
\text { than SUs) } \\
\text { Rapid onset and offset, hepatically excreted } \\
\text { (use w/renal insufficiency) }\end{array}$ \\
\hline \multicolumn{3}{|l|}{ OTHERS WIDIFFERENT ACTIONS } \\
\hline $\begin{array}{l}\text { Thiazolidinedione derivatives (TZD) } \\
\text { [eg, Pioglitazone, Rosiglitazone } \\
\text { (use with caution, see text)] }\end{array}$ & $\begin{array}{l}\text { Bind to peroxisome proliferator-activated } \\
\text { receptors (PPARs) and stimulate insulin } \\
\text { sensitive genes }\end{array}$ & $\begin{array}{l}\text { - Weight gain, peripheral edema (esp. w/insulin), } \\
\text { anemia, pulmonary edema, CHF, fractures } \\
\text { - Slow onset of action, no hypoglycemia, no reliance on } \\
\text { renal excretion, contraindicated in class III-IV CHF or } \\
\text { hepatic impairment }\end{array}$ \\
\hline $\begin{array}{l}\text { Glucagon-like peptide-I analogs } \\
\text { (eg, Exenatide, Liraglutide) }\end{array}$ & $\uparrow$ pancreatic insulin secretion & $\begin{array}{l}\text { Either favorable or neutral effect on weight } \\
\text { gain (delays gastric emptying, } \uparrow \text { satiety) }\end{array}$ \\
\hline $\begin{array}{l}\text { Dipeptidyl peptidase } 4 \text { inhibitors } \\
\text { (eg, Sitagliptin, Saxagliptin) }\end{array}$ & $\uparrow$ endogenous incretins & $\begin{array}{l}\text { - Avoid vildagliptin in hepatic impairment and stage IV-V } \\
\text { CKD, dose should be adjusted for renal } \\
\text { insufficiency } \\
\text { - Watch for immunosuppresive drug interaction } \\
\text { - Weight neutral, no hypoglycemia, ? } \beta \text { cell preservation }\end{array}$ \\
\hline
\end{tabular}

\section{Pharmacological management}

When lifestyle modification fails to achieve adequate glycemic control, medical intervention is recommended. Orally administered agents can be used either alone or in combination with other oral agents or insulin. The choice of pharmacologic therapy is based on the potential advantages and disadvantages associated with the different classes of oral agents. Table 3 summarizes the mechanisms of action and potential advantages and disadvantages of different classes of oral agents.

It is noteworthy that the results of the Dialysis Outcomes and Practice Patterns Study (DOPPS) demonstrated that in long-term hemodialysis patients, rosiglitazone was associated with a significantly higher all-cause (hazard ratio 1.59) and cardiovascular mortality and a 3.5 fold increase of hospitalizations due to myocardial infarction. ${ }^{62}$ In contrast to the DOPPS study results, in an analysis of the national cohort study consisting of more than 5,000 dialysis patients with type 2 diabetes, Brunelli et al ${ }^{63}$ observed a lower incidence of all-cause mortality in patients not on insulin versus insulin requiring diabetic patients. Similar studies in the transplant settings are lacking. Nonetheless, great caution should be exercised when rosiglitazone is used in the setting of kidney transplantation because all kidney transplant recipients should be regarded as having at least stage II-IV chronic kidney disease. It should be noted that rosiglitazone has been suspended in Europe since 2010.
Incretin-based therapy appears to provide an attractive treatment option for patients with NODAT owing to its favorable effect on weight reduction/weight neutrality. Data on its safety and efficacy in renal transplant recipients are currently lacking. A randomized, placebo-controlled, double-blind, prospective trial to evaluate the safety and efficacy of vildagliptin in patients with NODAT is currently underway. ${ }^{64}$ Caution should be exercised when these agents are used in the transplant setting, particularly with regards to drug-to-drug interactions. Vildagliptin should be avoided in patients with hepatic impairment and stage IV-V chronic kidney disease and the dose of sitagliptin should be adjusted for renal insufficiency. ${ }^{65}$

Finally, drug to drug interactions should be carefully considered. Interested readers are referred to references. ${ }^{66-69}$

\section{Summary}

NODAT is a common complication after solid organ transplantation and has variably been reported to have an adverse impact on patient and allograft outcomes. Risk stratification and intervention to minimize risk should be an integral part of the management of transplant recipients. Clinicians must be familiar with the patients' immune history prior to manipulating their immunosuppressive therapies in an attempt to ameliorate NODAT risk. When lifestyle modification fails 


\section{Table 4 Management of NODAT}

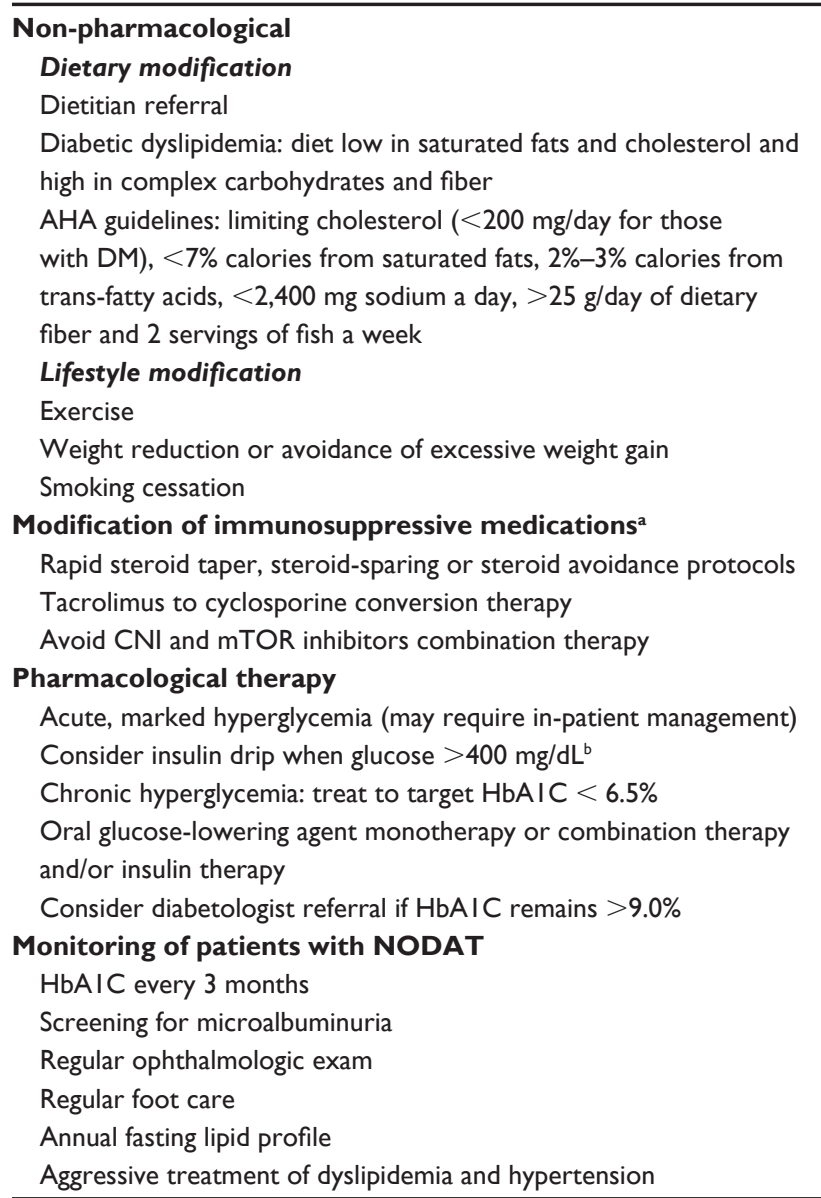

Notes: 'Clinicians must be familiar with the patients' immune history prior to manipulating their immunosuppressive therapy; 'The American College of Physicians expert panel recommends not using intensive insulin therapy to normalize blood glucose in general surgical and medical intensive care unit (SICU/MICU) patients with or without diabetes (reference 72). Studies in the transplant settings are lacking. The determination of target blood glucose for transplant recipients should be individualized at the discretion of the clinician.

Abbreviation: AHA, American Heart Association.

to achieve adequate glycemic control, medical intervention is often necessary.

The routine care of patients with NODAT should include an evaluation of hemoglobin A1C level every three months and regular screening for diabetic complications. It should be noted that hemoglobin A1C cannot be accurately interpreted within the first three months post transplantation due to various factors including possible blood transfusions in the early posttransplant period and the presence of anemia or impaired allograft function. Blood transfusions may render the test invalid until new hemoglobin is formed and the presence of anemia and kidney impairment can directly interfere with the $\mathrm{A} 1 \mathrm{C}$ assay. An artifactual reduction in $\mathrm{A} 1 \mathrm{C}$ level has been reported in islet cell transplant recipients taking dapsone for Pneumocystis carinii (P. jiroveci) prophylaxis.
The cause is yet unknown, but a reduction in red blood cell lifespan and/or hemolysis has been implicated. ${ }^{70}$

Fasting lipid profile should be measured annually. In transplant recipients with multiple CVD risk factors, more frequent monitoring of lipid profile should be performed at the discretion of the clinicians. Statins or the HMG-CoA reductase inhibitors are the most widely used lipid lowering agents in both the nontransplant and transplant settings. Table 4 summarizes suggested guidelines for the management of NODAT. ${ }^{71,72}$

\section{Disclosure}

The authors report no conflicts of interest in this work.

\section{References}

1. Davidson J, Wilkinson AH, Dantal J, et al. New-onset diabetes after transplantation: 2003 International Consensus Guidelines. Transplantation. 2003; 7:SS3-SS24.

2. Wilkinson AH, Davidson J, Dotta F, et al. Guidelines for the treatment and management of new-onset diabetes after transplantation. Clin Transplant. 2005;19:291-298.

3. Montori VM, Basu A, Erwin PJ, Velosa JA, Gabriel SE, Kudva YC. Posttransplantation diabetes: a systematic review of the literature. Diabetes Care. 2002;25(3):583-592.

4. Baid S, Cosimi AB, Farrell ML, et al. Posttransplant diabetes mellitus in liver transplant recipients: risk factors, temporal relationship with hepatitis $\mathrm{C}$ virus allograft hepatitis, and impact on mortality. Transplantation. 2001;72:1066-1072.

5. Knobler H, Stagnaro-Green A, Wallenstein S, et al. Higher incidence of diabetes in liver transplant recipients with hepatitis C. J Clin Gastroenterol. 1998;26:30-33.

6. Ye X, Kuo H-T, Sampaio MS, Jiang Y, Bunnapradest S. Risk factors for the development of new-onset diabetes mellitus after transplant in adult lung transplant recipients. Clin Transplant. 2010;DOI 10. 1111:1-7.

7. Bigam D, Pennington J, Carpentier A, et al. Hepatitis-C related cirrhosis: a predictor of diabetes after orthotopic liver transplantation. Hepatology. 2000;32(1):87-90.

8. Sharif A, Moore RH, Baboolal K. The use of oral glucose tolerance tests to risk stratify for new-onset diabetes after transplantation: an underdiagnosed phenomenon. Transplantation. 2006;82(12): 1667-1672.

9. Cosio FG, Pesavento TE, Osei K, Henry ML, Ferguson RM. Posttransplant diabetes mellitus: increasing incidence in renal allograft recipients transplanted in recent years. Kidney Int. 2001;59(2): $732-737$.

10. Kasiske BL, Snyder JJ, Gilbertson D, Maras AJ. Diabetes mellitus after kidney transplantation in the United States. Am JTransplant. 2003;3(2): 178-185.

11. Sulanc E, Lane JT, Puumala SE, Groggel GC, Wrenshall LE, Stevens RB. New-onset diabetes after kidney transplantation: an application of 2003 International Guidelines. Transplantation. 2005;80(7):945-952.

12. Martinez-Castelao A, Hernandez MD, Pascual J, et al. Detection and treatment of post kidney transplant hyperglycemia: a Spanish multicenter cross-sectional study. Transplant Proc. 2005;37(9):3813-3816.

13. Pham PT, Danovitch GM, Pham PC. The medical management of the renal transplant recipient. In: Johnson RJ, John Feehally, editors. Comprehensive Clinical Nephrology, 3rd ed. Philadelphia, PA: Mosby; 2007:1085-1101.

14. Hamer RA, Chow CL, Ong AC, McKane WS. Polycystic kidney disease is a risk factor for new-onset diabetes after transplantation. Transplantation. 2007;83:36-40. 
15. Ducloux D, Motte G, Vautrin P, Bresson-Vautrin C, Rebibou JM, Chalopin JM. Polycystic kidney disease as a risk factor for post-transplant diabetes mellitus. Nephrol Dial Transplant. 1999;14:1244-1246.

16. De Mattos AM, Olyaei AJ, Prather JC, Golconda MS, Barry JM, Norman DJ. Autosomal dominant polycystic kidney disease as a risk factor for diabetes mellitus following transplantation. Kidney Int. 2005;67:714-720.

17. Hjelmesaeth J, Hartmann A. Insulin resistance in patients with adult polycystic kidney disease. Nephrol Dial Transplant. 1999;14(10): 2521-2522.

18. Jindal RM, Revanur VK, Jardine AG. In: Hakim N, Stratta R, Gray D, editors. Immunosuppression and Diabetogenicity, 1st ed. (Pancreas and islet transplantation). New York: Oxford University Press; 2002: 247-27.

19. Hjelmesaeth J, Hartmann A, Kofstad J, Egeland T, Stenstrom J, Fauchald P. Tapering off prenisolone and cyclosporine the first year after renal transplantation: the effect on glucose tolerance. Nephrol Dial Transplant. 2001;16:829-835.

20. Hjelmesaeth J, Hartmann A, Kofstad J, et al. Glucose intolerance after renal transplantation depends upon prednisolone dose and recipient age. Transplantation. 1997;64(7):979-983.

21. Midtvedt K, Hjemesaeth J, Hartmann A, et al. Insulin resistance after renal transplantation: the effect of steroid dose reduction and withdrawal. J Am Soc Nephrol. 2004;15(12):3233-3239.

22. Luan FL, Steffick DE, Ojo AO. New-onset diabetes mellitus in kidney transplant recipients discharged on steroid-free immunosuppression. Transplantation. 2011;91(3):334-341.

23. Depcynski B, Daly B, Campbell LV, Chisholm DJ, Keogh A. Predicting occurrence of diabetes mellitus in recipients of heart transplants. Diabetes Med. 2000;17:15-19.

24. Woodward RS, Schnitzler MA, Baty J, et al. Incidence and cost of new onset diabetes mellitus among US wait-listed and transplanted renal allograft recipients. Am J Transplant. 2003;3(5):590-598.

25. Ekberg H, Tedesco-Silva H, Demirbas A, et al. Reduced exposure to calcineurin inhibitors in renal transplantation. N Engl J Med. 2007;357(25): 2562-2575.

26. Vincenti F, Friman S, Sceuermann E, et al. Results of an international, randomized trial comparing glucose metabolism disorders and outcome with cyclosporine versus tacrolimus. Am J Transplant. 2007;7(6): 1506-1514.

27. Heisel O, Heisel R, Balshaw R, Keown P. New onset diabetes mellitus in patients receiving calcineurin inhibitors: a systematic review and meta-analysis. Am J Transplant. 2004;4(4):583-595.

28. Meiser BM, Uberfuhr P, Fuchs A, et al. Single-center randomized trial comparing tacrolimus (FK506) and cyclosporine in the prevention of acute myocardial rejection. J Heart Lung Transplant. 1998;17(8): 782-788.

29. Maes BD, Kuypers D, Messiaen T, et al. Posttransplant diabetes mellitus in FK-506-treated renal transplant recipients: analysis of incidence and risk factors. Transplantation. 2001;72(10):1655-1661.

30. Cai TH, Esterl RM, Nichols F, Cigarroa F, Speeg KV, Halff GA. Improved immunosuppression with combination tacrolimus (FK506) and mycophenolic acid in orthotopic liver transplantation. Transplant Proc. 1998;30(4):1413-1414.

31. Bloom RD, Rao V, Weng F, Grossman RA, Cohen D, Mange KC. Association of hepatitis $\mathrm{C}$ with posttransplant diabetes in renal transplant patients on tacrolimus. J Am Soc Nephrol. 2002;13(5):1374-1380.

32. Teutonico A, Schena PF, Di Paolo S. Glucose metabolism in renal transplant recipients: effect of calcineurin inhibitor withdrawal and conversion to sirolimus. J AM Soc Nephrol. 2005;16(10): 3128-3135.

33. Johnston O, Rose CL, Webster AC, Gill JS. Sirolimus is associated with new-onset diabetes in kidney transplant recipients. J Am Soc Nephrol. 2008;19(7):1411-1418.

34. Bonato V, Barni R, Cataldo D, et al. Analysis of posttransplant diabetes mellitus prevalence in a population of kidney transplant recipients. Transplant Proc. 2008;40(6):1888-1890.
35. Kissebah AH, Vydelingum N, Murray R, et al. Relation of body fat distribution to metabolic complications of obesity. J Clin Endocrinol Metab. 1982;54(2):254-260.

36. Eckel RH. Mechanisms of the components of the metabolic syndrome that predispose to diabetes and atherosclerotic CVD. Proc Nutrition Soc. 2007;66(1):82-95.

37. Bayer ND, Cochetti PT, Kumar MSA, et al. Association of metabolic syndrome with development of new-onset diabetes after transplantation. Transplantation. 2010;90(8):861-866.

38. Kuypers DR, Claes K, Bammens B, et al. Early clinical assessment of glucose metabolism in renal allograft recipients: diagnosis and prediction of post-transplant diabetes mellitus. Nephrol Dial Transplant. 2008; 23(6):2033-2042.

39. Myslak M, Amer H, Morales P, et al. Interpreting post-transplant proteinuria in patients with proteinuria pre-transplant. Am J Transplant. 2006;6(7):1660-1665.

40. Roland M, Gatault P, Al-Naijjar A, et al. Early pulse pressure and lowgrade proteinuria as independent long-term risk factors for new-onset diabetes after kidney transplantation. Am J Transplant. 2008;8(8): 1719-1728.

41. Pham PC, Pham PM, Pham SV, Miller JM, Pham PT. Hypomagnesemia in patients with type 2 diabetes. Clin J Am Soc Nephrol. 2007;2(2): 366-373.

42. Van Laecke S, Van Biesen W, Verbeke F, De Bacquer D, Peeters P, Vanholder R. Postransplantation hypomagnesemia and its realtion with immunosuppression as predictors of new-onset diabetes after transplantation. Am J Transplant. 2009;9(9):2140-2149.

43. Van Laecke S, Desideri F, Geerts A, et al. Hypomagenesemia and the risk of new-onset diabetes after liver transplantation. Liver Transpl. 2010;16(11):1278-1287.

44. Cosio FG, Kudva Y, van der Velde M, Larson TS, et al. New onset hyperglycemia and diabetes mellitus are associated with increased cardiovascular risk after kidney transplantation. Kidney Int. 2005;67(6):2415-2421.

45. Bloom RD, Lake JR. Emerging issues in hepatitis C virus-positive liver and kidney transplant recipients. Am J Transplant. 2006;6(10): 2232-2237.

46. Delgado-Borrego A, Casson D, Schoenfeld D, et al. Hepatitis C virus is independently associated with increased insulin resistance after liver transplantation. Transplantation. 2004;77(5):703-710.

47. Simo R, Lecube A, Genesca J, Esteban JI, Hernandez C. Sustained virological response correlates with reduction in the incidence of glucose abnormalities in patients with chronic hepatitis $\mathrm{C}$ virus infection. Diabetes Care. 2006;29(11):2462-2466.

48. Kamar N, Toupance O, Buchler M, et al. Evidence that clearance of hepatitis $\mathrm{C}$ virus RNA after $\alpha$-interferon therapy in dialysis patients is sustained after renal transplantation. J Am Soc Nephrol. 2003; 14(8):2092-2098

49. Lehr H, Jao S, Waltzer WC, Anaise D, Rappaport FT. Cytomegalovirusinduced diabetes mellitus in a renal transplant recipient. Transplant Proc. 1985;17(5):2152-2154.

50. Hjelmesaeth J, Sagedal S, Hartmannn A, et al. Asymptomatic cytomegalovirus infection is associated with increased risk for new-onset diabetes and impaired insulin release after renal transplantation. Diabetologia 2004;47(9);1550-1556.

51. Hjelmesaeth J, Muller F, Jenssen T, Rollag H, Sagedar S, Hartmann A. Is there a link between cytomegalovirus infection and new-onset posttransplant diabetes mellitus? Potential mechanisms of virus induced $\beta$-cell damage. Nephrol Dial Transplant. 2005;20(11): 2311-2315.

52. Ojo AO. Cardiovascular complications after renal transplantation and their prevention. Transplantation. 2006;82(5):603-611.

53. Hjelmesaeth J, Hartmann A, Leivestad T, et al. The impact of early-diagnosed new-onset post-transplantation diabetes mellitus on survival and major cardiac events. Kidney Int. 2006;69(3): $588-595$. 
54. Boudreaux JP, McHugh L, Canafax DM, et al. The impact of cyclosporine and combination immunosuppression on the incidence of post transplant diabetes in renal allograft recipients. Transplantation. 1987;44(3):376-381.

55. Kuo H-T, Sampaio MS, Vincenti F, et al. Associations of pretransplant diabetes mellitus, New-Onset Diabetes Mellitus after Transplant, and acute rejection with transplant outcomes: an analysis of the Organ Procurement and Transplant Network/United Network for Organ Sharing (OPTN/UNOS) database. Am J Kidney Dis. 2010;56(6):1026-1028.

56. Pham PT, Pham PC 2008: Assessing the risk of post-transplantation diabetes mellitus with an oral glucose tolerance test. Nat Clin Pract Nephrol. 2008;4(11):600-601.

57. Mannon RB. Therapeutic management of posttransplant diabetes mellitus. Transplant Rev (Orlando). 2008;22(2):116-124.

58. Gerstein HC, Miller ME, Byinhton RP, et al. for the Action to Control Cardiovascular Risk in Diabetes Study group. Effects of intensive glucose lowering in type 2 diabetes. $N$ Engl J Med. 2008;358(24): 2545-2559.

59. Ismail-Beigi F, Craven T, Banerji MA, et al. for the ACCORD trial group. Effect of intensive treatment of hyperglycemia on microvascular outcomes in type 2 diabetes: an analysis of the ACCORD randomized trial. Lancet. 2010;376(9739):419-430.

60. Scheen AJ. Renin-angiotensin system inhibition prevents type 2 diabetes mellitus. Part 1. A meta-analysis of randomized clinical trials. Diabetes Metab. 2004;30(6):487-496.

61. Bosch J, Yusuf S, Gerstein HC, et al. Effect of ramipril on the incidence of diabetes. N Engl J Med. 2006;355(15):1551-1562.

62. Ramirez SP, Albert JM, Blayney MJ, et al. Rosiglitazone is associated with mortality in chronic hemodialysis patients. J Am Soc Nephrol. 2009;20(5):1094-1101.
63. Brunelli SM, Thadhani R, Ikizler TA, Feldman HI. Thiazolidinedione use is associated with better survival in hemodialysis patients with non-insulin dependent diabetes. Kidney Int. 2009;75(9):961-968.

64. Haidinger M, Werzowa J, Voigt H-C, et al. A randomized, placebocontrolled, double-blind, prospective trial to evaluate the effect of vildagliptin in new-onset diabetes mellitus after kidney transplantation. Trials. 2010;11:91.

65. Srinivasan BT, Jarvis J, Khunti K, Davies MJ. Recent advances in the management of type 2 diabetes mellitus: a review. Postgrad Med J. 2008;84(996):524-531.

66. Jindal RM, Hjelmesaeth J. Impact and management of posttransplant diabetes mellitus. Transplantation. 2000;70(Suppl 11):SS58-SS63.

67. Hatorp V, Hansen KT, Thomsen MS. Influence of drugs interacting with CYP3A4 on the pharmacokinetics, pharmacodynamics and safety of the prandial glucose regulator repaglinide. J Clin Pharmacol. 2003;43(6): 649-660.

68. Cheng AYY, Fantus IG. Oral antihyperglycemic therapy for type 2 diabetes mellitus. CMAJ. 2005;172(2):213-226.

69. Niemi M, Backman JT, Neuvonen M, Neuvonen PJ, Kivisto KT. Rifampin decreases the plasma concentrations and effects of repaglinide. Clin Pharmacol Ther. 2000;68(5):495-500.

70. Froud T, Faradji RN, Monroy K, et al. Dapsone-induced artifactual A1C reduction in islet transplant recipients. Transplantation. 2007;83(6): 824-825.

71. Pham PT, Pham PC, Danovitch GM. Posttransplant cardiovascular disease. Semin Nephrol. 2007;27(4):430-444.

72. Qaseem A, Humphrey L, Chou R, et al. Use of intensive therapy for the management of glycemic control in hospitalized patients: a clinical practice guideline from the American College of Physicians. Ann Intern Med. 2011;154(4):260-267.

\section{Publish your work in this journal}

Diabetes, Metabolic Syndrome and Obesity: Targets and Therapy is an international, peer-reviewed open-access journal committed to the rapid publication of the latest laboratory and clinical findings in the fields of diabetes, metabolic syndrome and obesity research. Original research, review, case reports, hypothesis formation, expert opinion and commentaries are all considered for publication. The manuscript management system is completely online and includes a very quick and fair peer-review system, which is all easy to use. Visit http://www.dovepress.com/testimonials.php to read real quotes from published authors. 